\title{
Suppressive Control of the Crustacean Pyloric Network by a Pair of Identified Interneurons. II. Modulation of Neuronal Properties
}

\author{
Jean-René Cazalets, Frédéric Nagy, and Maurice Moulins \\ Laboratoire de Neurobiologie et Physiologie Comparées, CNRS et Universite de Bordeaux I, F-33120 Arcachon, France
}

In the lobster Homarus, the 2 identified PS neurons have a strong suppressive modulatory effect on the activity of the pyloric network in the STG (Cazalets et al., 1990). In the present paper, we consider the effects of PS on individual pyloric neurons isolated from their partners in the network by cell photoinactivation and synaptic blockade. Three types of PS action are described: (1) a transient, EPSP-mediated depolarization of the PD, VD, and AB neurons; (2) a longlasting hyperpolarization concomitant with a loss of oscillatory properties in the PD and LP neurons; (3) a long-lasting depolarization without modification of oscillatory properties in the PY and IC neurons. The various effects of PS on isolated pyloric cells were consistent with the overall effects of PS on the intact pyloric network.

Studies on the mechanisms underlying the control of CPGs have shown the latter to be subject to numerous neuromodulatory inputs that are able to greatly modify CPG activity, generally via activating or enhancing influences. However, we have shown (Cazalets et al., 1987b, 1990) that one of the best described CPGs, the pyloric network in the STG of Crustacea, is the target of 2 identified neurons, the PS neurons that operate in an inactivating or suppressive mode. In the preceding paper (Cazalets et al., 1990) we described the modifications in the pyloric pattern that occur in response to PS discharge. Depending on PS firing frequency, these input neurons can produce either a complete, long-lasting cessation of rhythmic pyloric activity or induce longlasting modifications in the nature of the ongoing rhythm.

In the present paper, we analyze the cellular mechanisms that underlie such modifications in the expression of the pyloric pattern. In the intact network, the disruption of pyloric rhythmicity by PS firing is not uniform, but seems to involve different mechanisms from one pyloric neuron to another. For instance, after PS discharge the neurons controlling the pyloric valve (VD, IC) continue to burst, whereas the pacemakers (PD, $A B$ ) of the network are silenced. In addition, even when the effects on target cells are similar, the sensitivity of individual neurons is different. For example, the constrictor LP is much more sensitive to PS discharge than PD neurons.

In the present paper, we have examined these differential

\footnotetext{
Received Dec. 7, 1988; revised May 8, 1989; accepted June 23, 1989.

We thank R. Harris-Warrick, B. Johnson, P. Katz, J. Simmers, and A. J. Terney for critical comments on early drafts of this manuscript, and J. Simmers for help in preparing the final English version. This work was supported by a Ministère de la Recherche et Technologie Grant 85-C-1152 to M.M.

Correspondence should be addressed to M. Moulins at the above address.

Copyright (c) 1990 Society for Neuroscience $0270-6474 / 90 / 100458-11 \$ 02.00 / 0$
}

effects further by analyzing the specific influence of PS neurons on each pyloric cell type in an attempt to understand if and how the effects on single cells are consistent with the changes in the overall output pattern. For this we used the cell photoinactivation technique of Miller and Selverston (1979) and synaptic blockade to isolate in situ each of the 14 neurons from its presynaptic elements in the pyloric network. With these methods it has been possible to accumulate data that strongly suggest that the PS neurons act directly and differently on each pyloric neuron. Overall, 3 types of postsynaptic effect can be observed: (1) transient excitatory effects involving discrete EPSPs, (2) longlasting inactivating effects involving the suppression of regenerative oscillatory properties, and (3) long-lasting depolarizing effects without suppression of oscillatory properties. We conclude that PS neurons are multiaction neurons whose specific effects on individual pyloric neurons are consistent with the effects observed on the pyloric network as a whole.

\section{Materials and Methods}

Experiments were performed on adult European lobsters, Homarus gammarus. The experimental saline (Miller and Selverston, 1982) consisted of (in mM): $479 \mathrm{NaCl}, 12.74 \mathrm{KCl}, 13.7 \mathrm{CaCl}_{2}, 10 \mathrm{MgSO}_{4}, 3.9$ $\mathrm{Na}_{2} \mathrm{SO}_{4}, 5$ HEPES, pH 7.45 .

The in vitro preparation of the stomatogastric nervous system and the electrophysiological techniques used are as described in the accompanying paper (Cazalets et al., 1990).

\section{In situ isolation of pyloric neurons}

Photoinactivation. This technique, developed by Miller and Selverston (1979), allows removal of selected neurons from a neural circuit. It is based on the ability of some fluorescent dyes (e.g., Lucifer yellow) to cause cell death when injected and subscquently illuminated with blue light $(450-490 \mathrm{~nm})$. Intrasomatic injection of Lucifer yellow (3\% in aqueous solution) was made by passing negative current (ca. $10 \mathrm{nA}$ ) for 15-30 min through the dye-filled electrode. During exposure to blue light, a check was made that the dye had spread from the soma of the injected neuron(s) to its neuropilar ramifications and axon. The criteria for successful photoinactivation of a Lucifer-injected neuron were those of Miller and Selverston $(1979,1982)$.

Blockade of postsynaptic receptors. While photoinactivation was used to eliminate cholinergic inputs (from PDs, VD) to a selected postsynaptic neuron, other cells in the pyloric network (AB, LP, PY, IC; see Cazalets et al., 1990, figure $1 D$ ) are glutamatergic and their output synapses are readily blocked by picrotoxin (PTX) at $10^{-5} \mathrm{M}$ (Bidaut, 1980; Eisen and Marder, 1982). Thus, bath application of PTX in combination with photoinactivation allows one to completely isolate any chosen neuron from all others in the network. In the present report, the effects of PS on each isolated cell type were observed in at least 3 different experiments.

\section{Pharmacology}

Vaseline wells built around the various ganglia of the stomatogastric system in vitro allowed selective perfusion and perturbation of their 


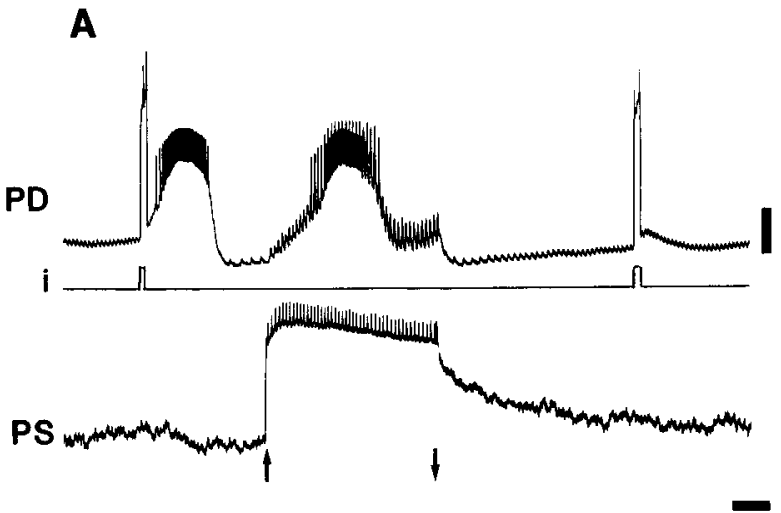

B

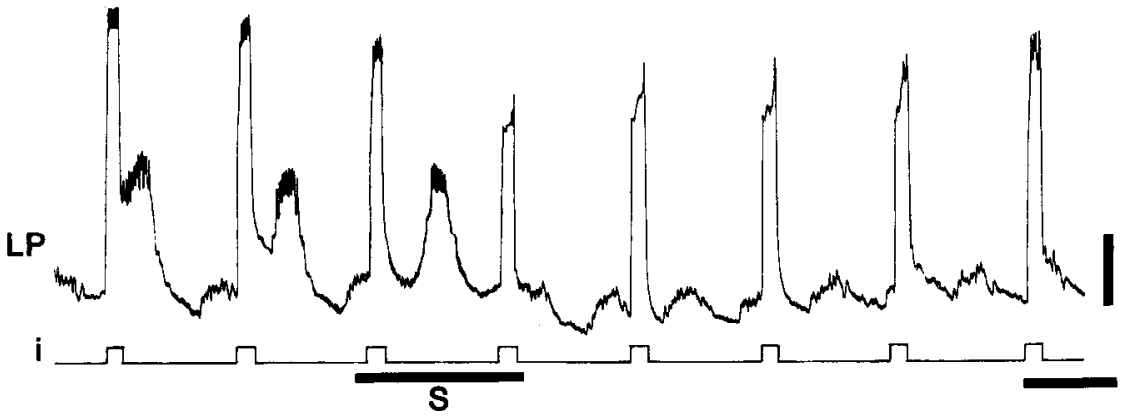

Figure 1. PS discharge suppresses the oscillatory properties of the PD and LP neurons. $A, B$, Before PS discharge, brief depolarizations of the PD neuron $(A)$ and LP neuron $(B)$, by intrasomatic current injection $(i)$, triggers burst-generating oscillations. Following PS discharge, elicited in $A$ by PS intrasomatic depolarization (arrows) and in $B$ by extracellular stimulation of the proximal ivn $(S ; 2$ sec at $30 \mathrm{~Hz})$, the same depolarizing pulses in PD and LP are now unable to trigger regenerative oscillations. Horizontal scale bars: $1 \mathrm{sec}$; vertical scale bars: $15 \mathrm{mV} ; 10 \mathrm{nA}$ in $A, 15$ nA in $B$. activity with saline of different ionic composition and/or with drugs. In particular, we used salines in which $\mathrm{Ca}^{21}$ was absent and $\mathrm{Mg}^{21}$ raised 6-fold (subsequently referred to as $0 \mathrm{Ca}^{2+}, 6 \mathrm{Mg}^{2+}$ ) to suppress synaptic activity in rostral ganglia (Fig. $3 \mathrm{~A}$ ) and thereby eliminate possible indirect pathways from PS to the STG. We checked that synaptic blockade was effective by stimulating the ventroposterior esophageal nerve known to contain sensory afferents (Robertson and Laverack, 1979), which influence the pyloric neurons via a synaptic relay in the commissural ganglia. D-Tubocurarine, PTX, and oxotremorine used were obtained from Sigma.

\section{Stimulation of the PS neurons}

Firing of the PS neurons was elicited either by intrasomatic injection of depolarizing current or by extracellular stimulation of their axons (see $S$ in Fig. $3 A$ ) in the ivn (see Cazalets et al., 1990).

\section{Results}

\section{Suppressive effects on the bursting activity of the $P D$ and $L P$} neurons

Loss of oscillatory properties. When the pyloric network is intact, the discharge of PS is followed by a long-lasting hyperpolarization of the PD and LP ncurons during which time they cease to oscillate (Cazalets et al., 1990). This suppression of oscillatory activity by PS could be due to 2 phenomena: (1) the membrane potential of PD and LP has been driven hyperpolarized to below threshold for activation of the voltage-dependant conductances underlying oscillation (Gola and Selverston, 1981; Russell and Hartline, 1982); (2) there is complete loss of an oscillatory capability in these cells, and whatever their membrane potential, they are no longer able to exhibit bursting behavior (Moulins and Cournil, 1982).

To distinguish between these 2 possibilities we used depolarizing current injection to test for an active bursting capability in PD and LP neurons before and after PS discharge. Before PS discharge both cells displayed full regenerative depolarizations in response to brief depolarizing pulses (left part of Fig. 1, $A$, $B)$. Immediately after PS discharge, however, the same depolarizing pulses failed to trigger oscillatory potentials (right part of Fig. 1, $A, B$ ). Note that when it fires, PS also evokes large EPSPs in the PD neuron (see Cazalets et al., 1990). Moreover, sustained depolarizing currents at different amplitude were unable to induce oscillation in the PD and LP neurons after PS discharge. This would not be expected if straightforward synaptic hyperpolarization was responsible for the absence of oscillatory activity. Thus, these experiments strongly suggest that discharge of the PS neuron results in suppression of the oscillatory properties of the pacemakers PD and the constrictor neuron LP.

By using the same current injection tests, it was possible to observe the recovery of the oscillatory capability of these pyloric elements after a PS discharge. In the experiment of Figure 2, brief depolarizations were applied to $\operatorname{PD}(A)$ and LP $(B)$ neurons at different intervals after PS discharge. At $4 \mathrm{sec}$ after a brief PS discharge ( $2 \mathrm{sec}, 30 \mathrm{~Hz}$ ) the PD neuron exhibited a purely passive response; after $8 \mathrm{sec} P D$ produced a delayed and relatively weak oscillation, while at $12 \mathrm{sec}$ a full-blown bursting potential was produced. For the LP neuron, the response was purely passive $18 \mathrm{sec}$ after the PS discharge; it was active, though late and attenuated, at $38 \mathrm{sec}$; and it showed full recovery only after ca. $45 \mathrm{sec}$. These observations are not only consistent with previously described (Cazalets et al., 1990) long-term suppressive effects of PS with LP being more sensitive than PD ncurons, but they also show that the influence of PS is not an all-or-none phenomenon, evoking intermediate steps between a "full" oscillatory and a nonoscillatory state in its target neurons.

The PS neuron acts directly on the PD and LP neurons. The preceding results were obtained from preparations in which the STG was left attached to anterior centers, namely the OG and 
Figure 2. The suppressive effect of PS on the regenerative properties of the $P D$ and LP neurons is long-lasting and graded. Brief depolarizing current pulses are injected into a $\mathrm{PD}(A)$ and $\mathrm{LP}(B)$ cell body at various times after PS discharge ( $2 \mathrm{sec}, 30 \mathrm{~Hz}$ ). Pulses in PD and LP at $4 \mathrm{sec}$ and $18 \mathrm{sec}$, respectively, after PS discharge evoke passive responses only. The same tests at $8 \mathrm{sec}$ (PD) and $38 \mathrm{sec}$ (LP) elicit a delayed and attenuated regenerative response in the 2 pyloric neurons. Complete recovery from the suppressive effects of PS is observed after $12 \mathrm{sec}$ for PD, and only at $50 \mathrm{sec}$ for LP. Horizontal scale bar: $150 \mathrm{msec}$ in $A, 100 \mathrm{msec}$ in $B$; vertical scale bars: $20 \mathrm{mV}, 6 \mathrm{nA}$ in $A ; 15 \mathrm{mV}$, $6 \mathrm{nA}$ in $B$.

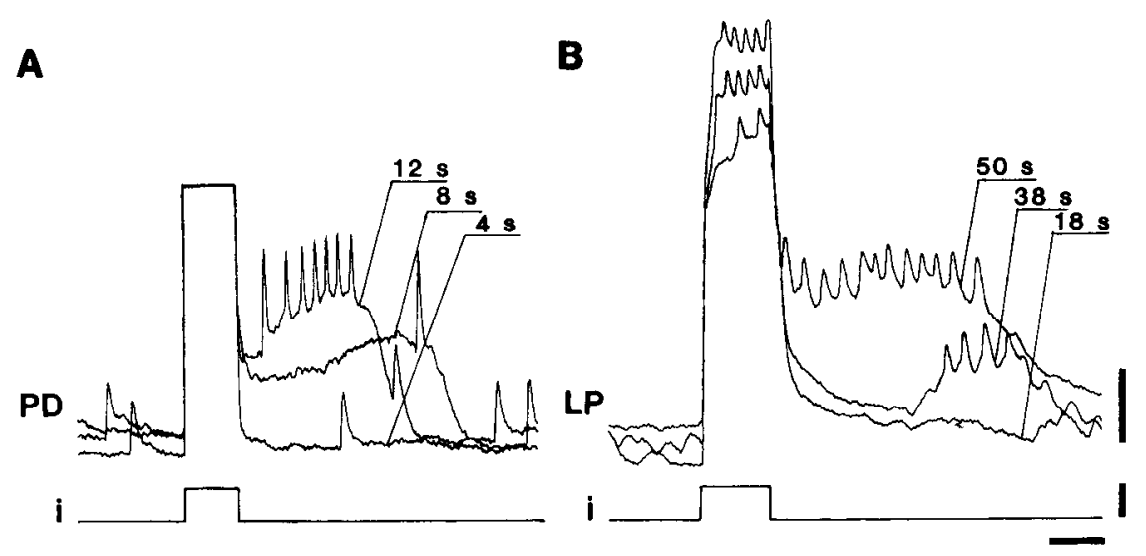

COG (see Fig. 3A). Therefore, we could not exclude the possibility that the effects of PS discharge were due to an indirect polysynaptic pathway via one or several neurons in the $O G$, the COGs, and/or the STG. In addition to such an indirect pathway, the possibility remains that PS exerts its influence on pyloric neurons via a "network effecl," i.e., an indirect effect via other elements of the pyloric network itself.

To eliminate all possible polysynaptic pathways through the COGs and the $O G$, we perfused the latter with a $0 \mathrm{Ca}^{2+}, 6 \mathrm{Mg}^{2+}$ saline (see Materials and Methods) to block all synaptic activity in these centers (Fig. 3A). Under these conditions, however, the pyloric neurons cease to oscillate. This is probably due to the loss of input to the STG from neurons, located in the rostral ganglia, and whose neuromodulatory permissive action is neccssary to sustain the oscillatory properties of pyloric neurons (Moulins and Cournil, 1982). In such cases rhythmic behavior in STG neurons was elicited by bath application of the cholinergic muscarinic agonist oxotremorine (Marder and PaupardinTritsch, 1978; Anderson, 1980; Nagy et al., 1985). Figure $3 B$ shows that when synaptic activity is blocked in the anterior centers and in the presence of oxotremorine on the STG, PS firing $(\mathrm{S}, 30 \mathrm{~Hz})$ still exerts a bimodal influence on the penetrated PD neuron: i.e., (1) large EPSPs evoked directly by PS firing and (2) subsequent cessation of rhythmic activity. Under the same experimental conditions, a similar PS-evoked inactivation is also observed in the LP neuron, further indicating that the suppressive action of PS is exerted directly at the level of the STG.

To address the possibility of a "network effect" of PS we then studied the consequences of PS discharge on the PD and LP neurons after isolation from the other neurons of the pyloric network. Again, synaptic activity was blocked in the anterior centers. Two such experiments are shown in Figure $3, C, D$ where PD (Fig. 3C ) and LP (Fig. 3 $D_{l}$ ) neurons were isolated synaptically from all their network partners by photoinactivation and pharmacological blockade with PTX (see Materials and Methods). As already seen for the intact network, isolated pyloric neurons cease to oscillate spontaneously when the anterior centers are perfused with $0 \mathrm{Ca}^{2+}, 6 \mathrm{Mg}^{2+}$ saline. Under these conditions, importantly, PS firing still evokes a large EPSP in PD (Fig. $3 C_{2}$ ) and a prolonged hyperpolarization of both PD and LP (Fig. 3, $C_{2}, D_{2}$ ). Without additional synaptic blockade of the anterior centers, the LP and PD neurons continue to oscillate when isolated from the pyloric network (Bal et al., 1988) and again PS discharge causes long-lasting cessation of this rhythmic activity.

The above data, together with the fact that no neuron presynaptic to the pyloric neurons and having similar effects is known to exist in the STG, strongly suggest that the pathway mediating the suppressive effects of PS on PD and LP is monosynaptic.

Pharmacological characterization of PS effects on $P D$ and $L P$. Other than GABA, none of the putative neurotransmitters whose actions on the PD and LP neurons have been studied to date (see review by Marder, 1987) could cause the long-lasting suppressive effects of PS on PD and LP (Cazalets et al., 1987a). Histamine, which mediates a relatively long-lasting, discrete IPSP on the PD neurons, does not influence the LP neuron (Claiborne and Selverston, 1984a). On this basis, we tried to block the suppressive action of PS by bath application of substances known to antagonize the action of GABA in the STG (PTX) and in other systems (bicuculline, curare). However, none of these drugs were seen to antagonize the suppressive effect of PS, although several (including PTX at high concentration, $10^{-3}$ M) were able to considerably reduce or abolish completely the PS-evoked EPSP in the PD neuron.

By contrast, bicuculline was ineffective in blocking both the suppressive effect and the EPSP. We also tested curare, which normally interacts with nicotinic receptors but can sometimes act as a GABA antagonist (Leake and Walker, 1980). However, curare was also without effect on the suppressive influence of PS on both PD and LP (Fig. $4, A_{l}, A_{2}$ ), although it almost completely blocked the EPSP of PS in PD neurons (Fig. $4, B_{l}$, $\left.B_{2}\right)$.

\section{Long-lasting activating effects of PS on PY and IC neurons}

With an intact pyloric network, firing of PS long-lastingly transforms bursting activity of PY neurons into a tonic discharge (Cazalets et al., 1990). We show in Figure 5 that this is due to a strong depolarization of the PY neurons subsequent to PS firing, but importantly, not to a suppression of their intrinsic ability to generate oscillations. In this experiment the STG was left attached via the stn to the anterior centers and the pyloric network remained intact. Under these conditions, continuous tonic discharge evoked in PS neurons produced its expected effects, i.e., cessation of all rhythmic activity of the 3 pyloric cell types, PD, LP, and PY. PD received an EPSP 1 for 1 with each PS action potential; LP was hyperpolarized and remained 


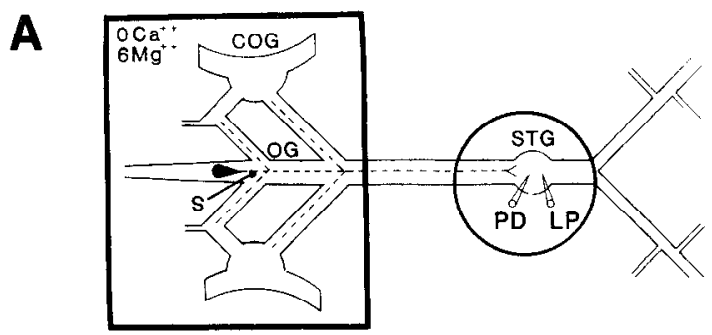

B
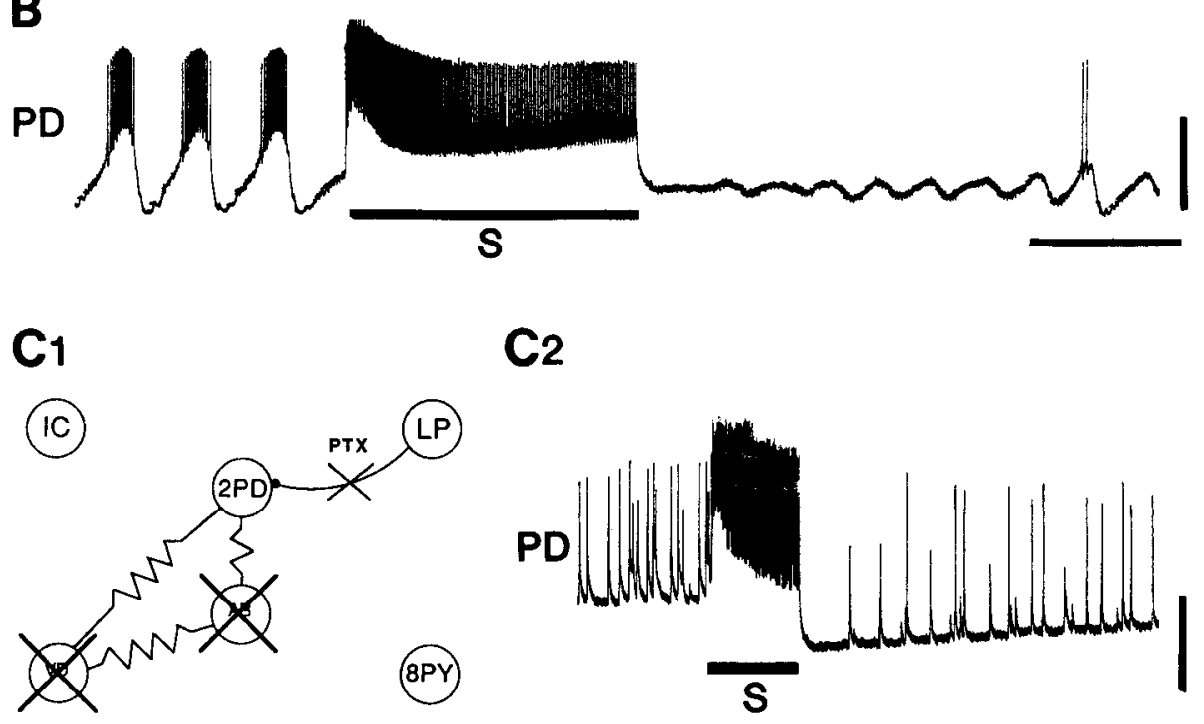

$\mathrm{C}_{2}$

D1

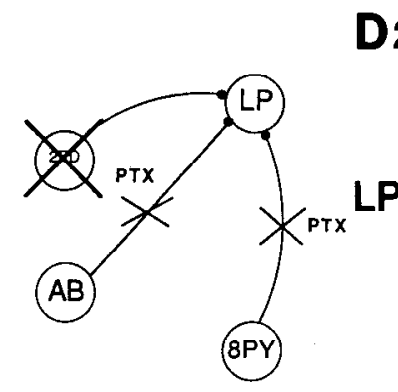

D2

(IC)

(v)
Figure 3. The suppressive effect of PS on PD and LP neurons is direct. $A$, Diagram of the stomatogastric nervous system in vitro showing the stomatogastric ganglion (STG), the commissural ganglia $(C O G)$, and the cell body of a PS neuron located in the ivn near the esophageal ganglion $(O G)$. Dotted lines represent the axonal projections of a PS neuron. Experiments in $B-D$ were performed with the anterior ganglia perfused selectively (square) with a $0 \mathrm{Ca}^{2+}$, $6 \mathrm{Mg}^{2+}$ saline to block synaptic transmission in these centers. PS discharge ( $2 \mathrm{sec}, 30 \mathrm{~Hz}$ ) was elicited by stimulation of the ivn $(S)$. $B$, During blockade of synaptic activity in the anterior centers, oscillatory activity in the PD neurons was maintained by perfusing the STG (circle) with the muscarinic agonist oxotremorine (see text). Under these conditions, PS discharge causcs cessation of rhythmic activity in the penetrated $\mathrm{PD}$ cell. $C, D$, The $\mathrm{PD}$ and $\mathrm{LP}$ neurons were isolated from other neurons of the pyloric network by photoinactivation of selected presynaptic neurons $\left(C_{l}, D_{l}\right.$, crossed cell bodies) and blockade of remaining functional synapses by perfusing the STG with $10^{-5}$ $\mathrm{M}$ picrotoxin $(P T X)$. Because synaptic activity was also blocked in the anterior centers, the PD and LP neurons did not oscillate spontaneously. Under these conditions, PS stimulation $(S)$ provokes a long-lasting hypcrpolarization of the PD $\left(C_{2}\right)$ and $\mathrm{LP}\left(D_{2}\right)$ neurons. Note the large PS-evoked EPSPs that remain evident in PD. Horizontal scale bars, $2 \mathrm{sec}$; vertical scale bars, $10 \mathrm{mV}$. silent with the PY neuron discharged tonically (beginning of the record, Fig. $5 A$ ). However, subsequent maintained hyperpolarization of the PY neuron by intrasomatic injection of negative current (Fig. 5A, between arrows) allowed the expression of oscillatory behavior in this neuron and rhythmic bursts of action potentials. Endogenous regenerative properties underlay this rhythmic behavior of PY, since the activity did not occur in presynaptic pyloric neurons (cf. LP, PD traces in Fig. 5A), and it was possible to trigger premature oscillations by brief depolarizations and to modify the frequency of oscillation in a voltage-dependent manner by injecting different levels of hyperpolarizing current (not shown).

Thus, during or after PS discharge, the PY neurons, although not spontaneously oscillating, maintain their intrinsic ability to produce regenerative depolarizations. That PY does not oscillate is probably due to the fact that during PS firing, PY is strongly depolarized, and the cell is unable to express voltagedependent conductances responsible for active repolarization.
After PS firing, the PD and LP neurons remain hyperpolarizedthey no longer inhibit the PYs--and this may partially explain why the latter remain depolarized. However, this sustained depolarization of PY is also due to a direct effect of PS. In the experiment of Figure $5 B$ the PY neurons were isolated from other pyloric network elements (Fig. $5 B_{2}$ ), and possible polysynaptic pathways via the anterior centers were blocked with a $0 \mathrm{Ca}^{2+}, 6 \mathrm{Mg}^{2+}$ saline (Fig. $5 B_{l}$ ). As noted above (Fig. 3), this causes a cessation of rhythmic pyloric activity, the elements in the network being unable to develop regenerative bursts of action potentials. Under these conditions, however, the discharge of PS provokes a long-lasting depolarization of an isolated PY neuron and an enhancement of its firing frequency (Fig. $5 B_{3}$ ). Here again, this effect cannot be attributed to any known local interneuron in the STG and is therefore considered to be monosynaptic.

Thus, we conclude that under normal conditions with the pyloric network intact, the depolarization of the PY neuron after 

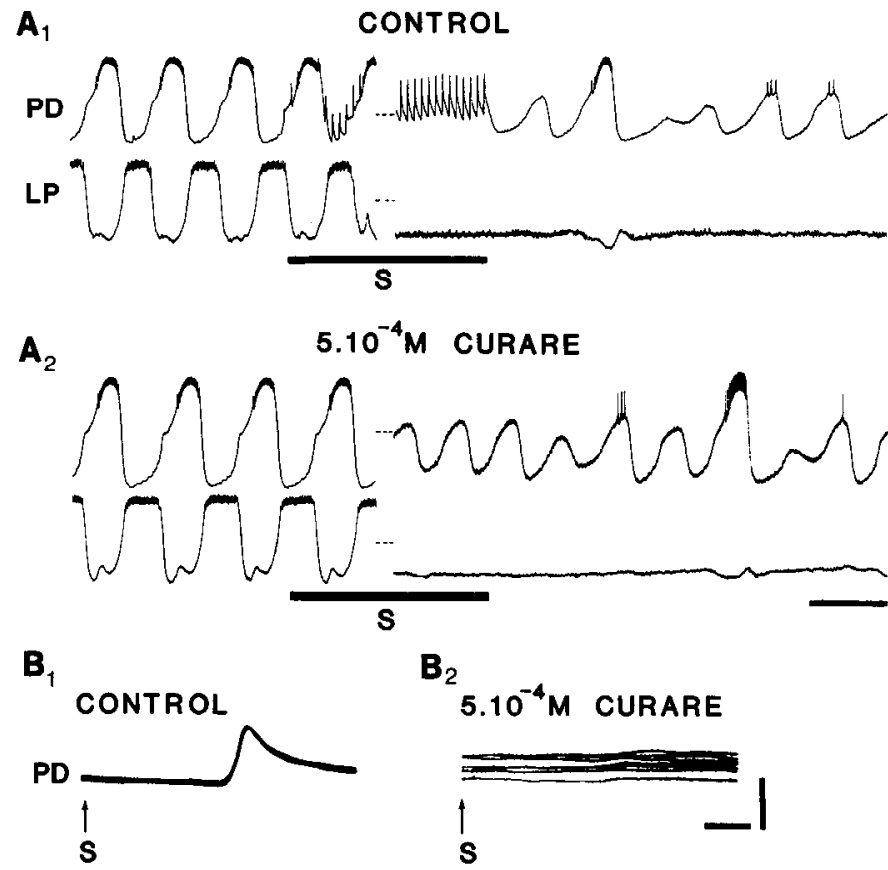

$5.10^{-4} \mathrm{M}$ CURARE

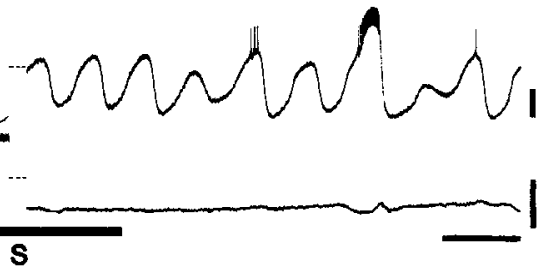

$\mathbf{B}_{2}$

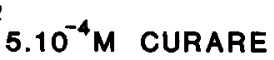

Figure 4. Curare blocks the PS-evoked EPSP in PD but not the suppressive effect of PS. $A_{l}$, Control; PS discharge causes EPSPs in PD, reduces $P D$ oscillatory behavior, and completely suppresses LP activity. $A_{2}$, In the presence of curare, the EPSP in PD disappears but the suppressive effect of PS persists. $B_{i}$, Single shock stimulation of the ivn $(S)$ is followed at constant latency by an EPSP in PD. $B_{2}$, The EPSP is abolished in the presence of curare. Each panel in $B$ consists of 7 oscilloscope sweeps triggered by PS stimulation. Horizontal scale bars: $A$, $1 \mathrm{sec} ; B, 10 \mathrm{msec}$; vertical scale bars: $A, 10 \mathrm{mV} ; B, 20 \mathrm{mV}$.

PS firing results from (1) a direct depolarizing effect from PS and (2) a "network effect," resulting from a relcase from inhibition by the PD and LP neurons. Noteworthy also is that in the experimental conditions of Figure $5 B$, where the rostral ganglia were under modified saline and the PY neuron was unable to produce oscillations prior to PS discharge, hyperpolarizing the cell (as in Fig. 5A) immediately following PS stimulation (not shown) still did not reveal an oscillatory capability. Thus, PS does not appear to influence the oscillatory properties of PY neurons, either by suppressing these properties when the target neurons are oscillating spontaneously (Fig. $5 A$ ) or by inducing them when the PYs are quiescent (Fig. $5 B$ ).

The effect of PS on the IC neuron is similar to that of PY. It was demonstrated in the preceding paper that the IC neuron does not stop oscillating during tonic discharge of PS (Cazalets et al., 1990). Moreover, Figure $6 A$ shows that a phasic discharge of PS causes a long-lasting excitation of the $I C$ neuron, with an increase in both its bursting ( $25 \%$ ) and firing (35\%) frequencies. By using the same experimental procedures as for the PY neuron, i.e., blocking synaptic activity in the COGs (Fig. $6 B_{1}$ ) and isolating IC from the pyloric network (Fig. $6 B_{2}$ ), it is evident that the PS neuron exerts an activating influence that is direct and long-lasting, on the IC neuron (Fig. $6 B_{3}$ ). We have checked by injection of current pulses in the soma of IC, that as for PY, this activation by PS does not involve induction of regenerative properties in the pyloric cell (not shown).

From these experiments we conclude that, in addition to a long-lasting suppressive effect on the regenerative properties of some neurons (viz. PD and LP), PS can also directly control the activity of other neurons (PY and IC) by depolarizing them long-lastingly, but without causing any change in their existing oscillatory properties.

\section{Transient excitatory effects of $P S$ on VD and $A B$ neurons}

In an intact pyloric network the VD neuron does not stop oscillating during or after PS firing (Cazalets et al., 1990). Consistent with this observation, we show here that when VD is isolated from other pyloric neurons, this element is activated by PS discharge. After in situ isolation (Fig. $7 A_{i}$, see below), the discharge of PS elicits large-amplitude summating EPSPs in VD which strongly depolarize the cell throughout PS activity (Fig. $7 A_{2}$ ). In this experiment $\mathrm{VD}$ was isolated from all other pyloric neurons except LP (Fig. 7 $A_{1}$ ); however, since LP is hyperpolarized by PS, this remaining presynaptic element cannot be implicated in the observed modifications of VD activity: The decrease in oscillation frequency of $\mathrm{VD}$ immediately following the relatively long $(10 \mathrm{sec})$ discharge of PS is probably due to posttetanic depression, as suggested by the following obscrvations. First, a similar poststimulus decrease in VD oscillation frequency occurs if the cell is made to fire at high frequencies by direct intrasomatic current injection (not shown). Second, when the PS-derived EPSPs in VD are blocked by curare (Fig. 7B), PS discharge no longer modifies the activity of VD. By contrast, PS discharge still suppresses oscillations in the neurons PD and LP in the presence of curare (Fig. 4), which also blocks PSderived EPSPs in the PD neuron. We conclude, therefore, that transient synaptic excitation is the only effect of PS discharge on the VD neuron.

As for VD, PS exerts transient excitation only on the $A B$ interneuron, although in an intact network it elicits additional long-lasting cessation of $\mathrm{AB}$ oscillatory activity. The recordings shown in Figure 8 were obtained from the same $A B$ neuron, before (Fig. $8 A$ ), and after (Fig. $8 B$ ) isolation from the pyloric network. In control conditions (Fig. $8 A$ ), PS has effects on $\mathrm{AB}$ that are similar to those on PD neurons, that is, EPSPs during PS discharge, which lead to a strong depolarization of $A B$, and subsequently, a prolonged hyperpolarization with cessation of the interneuron's oscillatory activity. Figure $8 B$ shows that when the $A B$ neuron is isolated from the network, an identical discharge of the PS neurons still produces a transient (EPSP-derived) excitation of $A B$, but fails to produce the subsequent hyperpolarization and long-lasting cessation of $A B$ oscillation. Therefore, the PS neuron does not appear to exert direct longlasting modulatory influences on the oscillatory properties of $A B$. That $A B$ ceases to oscillate in the intact network after PS firing can be attributed to its electrical coupling with the PD neurons, which are themselves long-lastingly inactivated and hyperpolarized by PS neuron discharge.

In conclusion, it appears that while the overall effect of PS discharge on the pyloric network is to suppress rhythmic activity, the mechanisms involved are different from one neuron to the next. The multiple actions of the PS neuron on the pyloric network are summarized in Figure 9. Its effects include: (1) EPSPs in the dilator neurons (AB, PD, VD) during PS discharge; at high frequency these EPSPs strongly depolarize the dilators, which cease to oscillate; (2) a direct long-lasting suppression of the oscillatory properties of the PD and LP neurons, and an indirect (via electrical coupling between PDs and $A B$ ) cessation of rhythmic activity in $\mathrm{AB}$; (3) a long-lasting depolarization of the PYs and IC, which in the case of the PY neurons also provokes a cessation of spontaneous rhythmic activity. 
A PS stim $6 \mathrm{~Hz}$

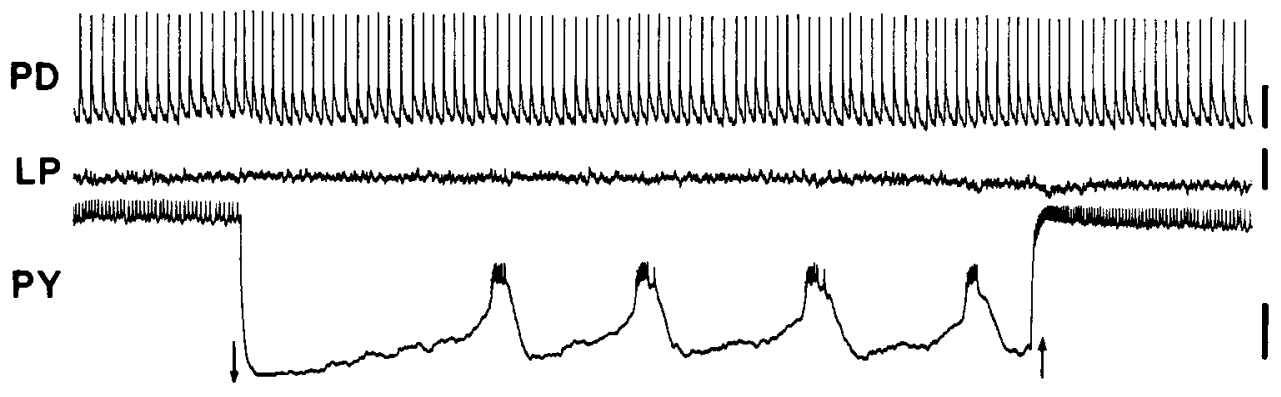

$\mathbf{B}_{1}$
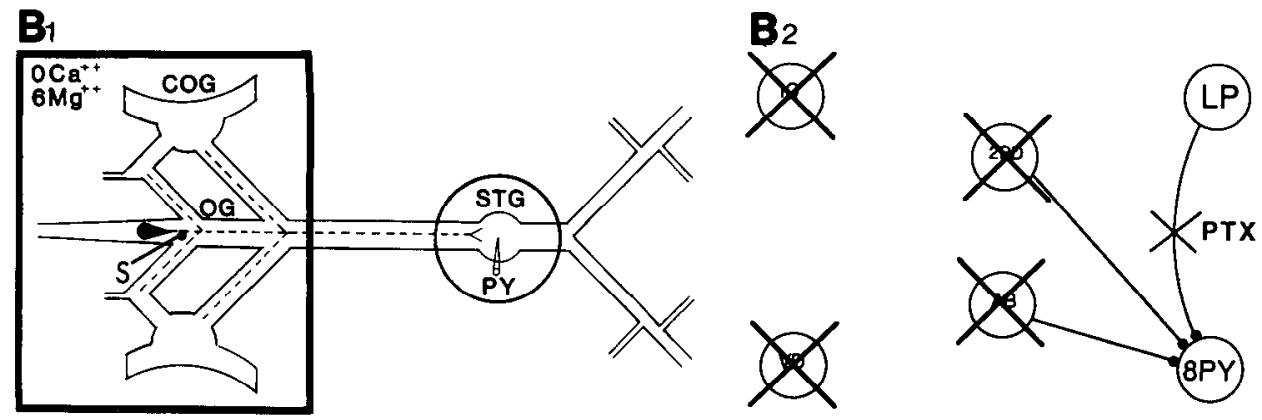

B3

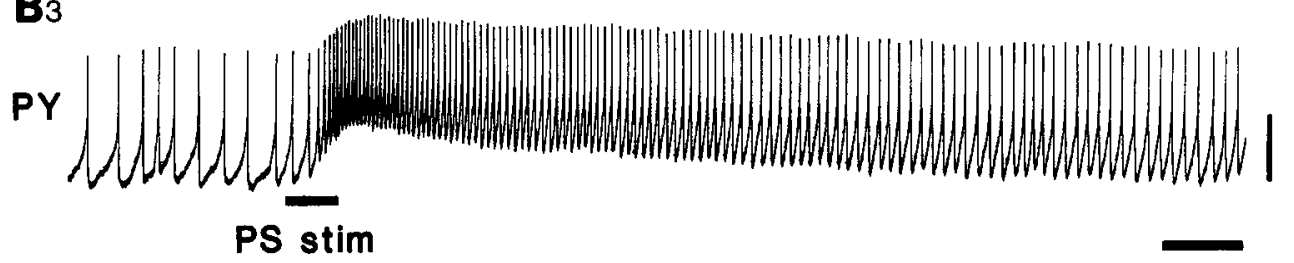

Figure 5. PS discharge provokes longlasting depolarization of the PY neurons but does not affect their oscillatory properties. $A$, Tonic discharge of PS causes a cessation of oscillatory activity in PD, LP, and PY neurons. However, intrasomatic injection of hyperpolarizing current (arrows) into PY allows expression of an endogenous oscillatory capability. $B$, Long-lasting depolarization of the PY neurons by PS is direct. $B_{l}$, Diagram of experimental preparation; synaptic activity in the anterior ganglia is abolished with a $0 \mathrm{Ca}^{2+}, 6$ $\mathrm{Mg}^{2+}$ saline (perfusion square); the STG is perfused with saline containing $10^{-5}$ M PTX (circle). $B$, PY neurons were isolatcd by photoinactivation of appropriate presynaptic neurons in the network (crossed cell bodies) and perfusion of PTX. $B_{3}$, In this situation, PS discharge ( $2 \mathrm{sec} ; 30 \mathrm{~Hz}$ ) provokes a longlasting depolarization of a PY neuron and a consequent enhancement of its firing frequency. Horizontal scale bar: 2 sec; vertical scale bars: $A, 10 \mathrm{mV}$ for $\mathrm{PD}$ and PY, $5 \mathrm{mV}$ for LP; $B, 15 \mathrm{mV}$.

\section{Discussion}

$P S$ neurons act directly on each pyloric neuron

Since PS projects to the OG and COG in addition to the STG (Cazalets et al., 1990), it is possible that PS could exert some of its effects on the pyloric network via polysynaptic pathways through the anterior ganglia. However, the following suggests that this is not the case and that the effects associated with PS discharge are due to a direct action on pyloric neurons in the STG.

First, PS appears to make monosynaptic connections with pyloric dilator neurons (PD, VD, AB) (Cazalets et al., 1990). PS action potentials are correlated 1:1 with EPSPs in these neurons, at PS firing frequencies as high as $60 \mathrm{~Hz}$, and in conditions either where synaptic activity is blocked in the anterior centers (OG and COG) with $0 \mathrm{Ca}^{2+}, 6 \mathrm{Mg}^{2+}$ saline, or the threshold for spiking is raised in the same ganglia with a $6 \times\left[\mathrm{Mg}^{2+}\right]$ saline (Berry and Pentreath, 1976).

The determination of the mono- or polysynaptic nature of other PS effects (i.e., suppression of PD and LP oscillatory properties; activation of PY and IC) is more problematic, since these are not associated with any discrete postsynaptic event. Despite this difficulty, it is evident that these long-lasting PS effects still persist when synaptic activity is blocked in the anterior centers. Moreover, given a long-lasting inactivation of $\mathrm{AB}$ by $\mathrm{PS}$, none of these effects can be due to: (1) a "network effect," since they persist for isolated pyloric neurons; (2) some other neurons located in the STG where all 30 neurons have been characterized and no element has been observed to have such effects on pyloric neurons. A possibility still remains that PS acts presynaptically in the STG, influencing other inputs descending from the anterior centers. Currently we have no way of testing this possibility.

\section{Long-lasting suppressive effects of PS}

The action of PS on the PD and LP neurons results in a suppression of their regenerative properties; i.e., they switch from an oscillatory to a nonoscillatory state. During PS discharge the PD neurons depolarize with large EPSPs and they fire at high frequency. The cessation of oscillatory activity in these neurons after termination of PS firing, however, cannot be due either to a posttetanic depression following their own high-frequency firing, since the suppressive effect still persists when the EPSPs (and the ensuing high-frequency firing of the PDs) are blocked by curare (Fig. 4) or PTX.

Suppression of regenerative properties of the PD and LP neurons is probably the main cause of the long-lasting cessation of pyloric filter rhythmicity that occurs in response to PS discharge in an intact pyloric network. Suppression of these oscillatory properties is accompanied by a prolonged hyperpolarization of the PD neurons. This hyperpolarization is most likely transmitted indirectly to the $\mathrm{AB}$ interneuron via the strong electrical 
A

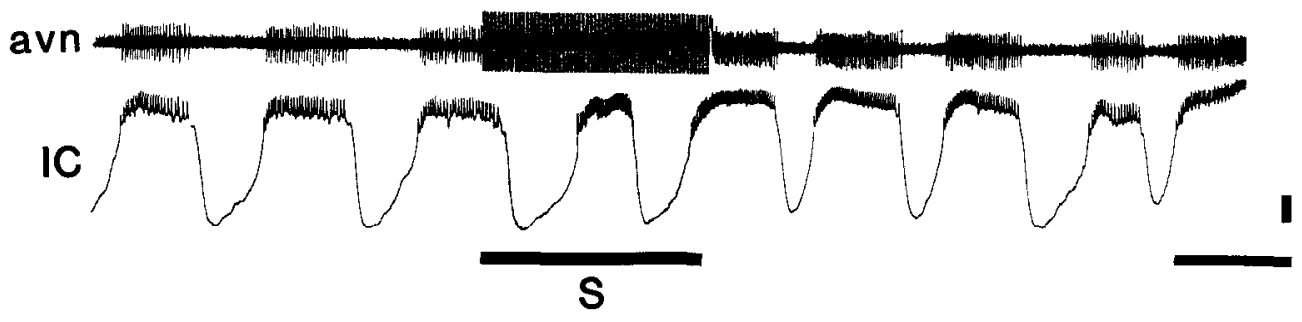

$\mathbf{B}_{1}$

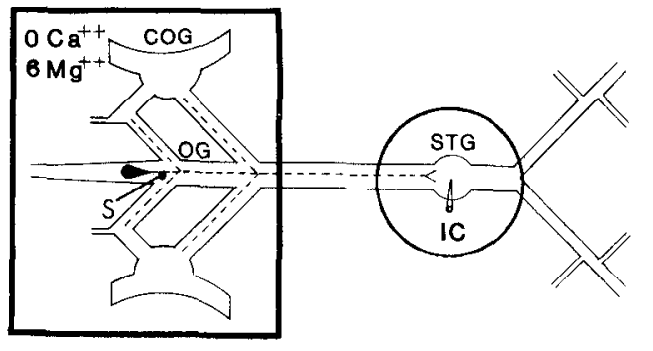

$\mathbf{B}_{2}$

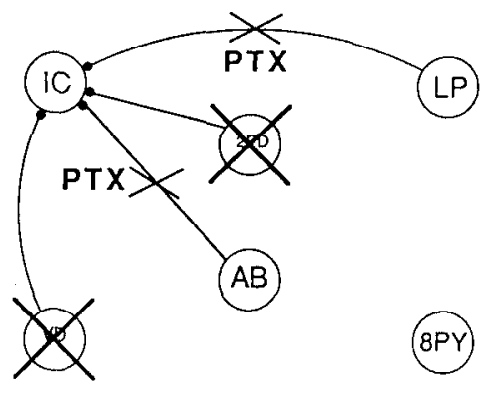

$\mathbf{B}_{3}$

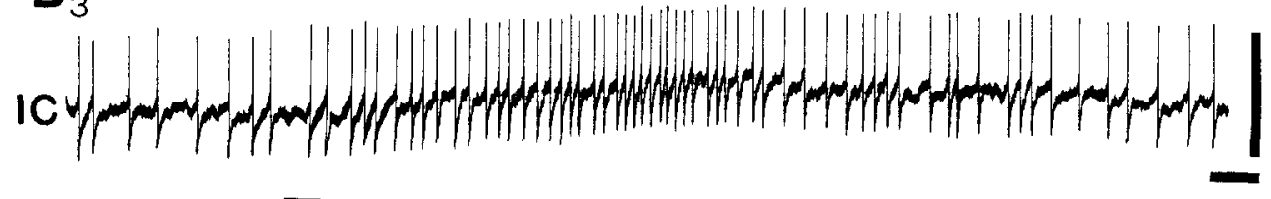

S
Figure 6. PS discharge induces a longlasting activation of the IC neuron. $A$, Stimulation of the ivn and hence PS ( $S$; $2 \mathrm{sec}, 30 \mathrm{~Hz}$ ) enhances the pyloric activity (burst frequency and spike intensity) of an impaled IC neuron. $B$, PS discharge causes long-lasting depolarization of the IC neuron. $B_{l}$, Diagram the anterior ganglia is blocked with 0 $\mathrm{Ca}^{2+}, 6 \mathrm{Mg}^{2+}$ saline (square). $B$, The IC neuron is isolated from other neurons in the pyloric network by photoinactivation of presynaptic neurons (crossed cell bodies) and addition of PTX in the saline that perfuses the STG (circle). $B_{3}$, Subsequently, PS discharge ( $2 \mathrm{sec} ; 30$ $\mathrm{Hz}$ ) provokes a sustained depolarization of the IC neuron and an increase in its firing frequency. Horizontal scale bars, $1 \mathrm{sec}$; vertical scale bars, $5 \mathrm{mV}$.

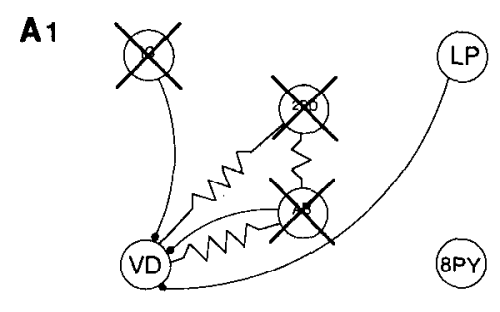

A2

Figure 7. The PS neuron transiently excites the VD neuron. $A_{l}$, The VD neuron was partially isolated (see text) by photoinactivating the IC neuron and neurons $\mathrm{PD}, \mathrm{AB}$ with which VD is electrically coupled (crossed cell bodies). $A_{2}$, Under these conditions, PS discharge elicited by extracellular stimulation of its axon in the ivn $(S ; 10 \mathrm{sec}, 30 \mathrm{~Hz})$, evokes large EPSPs in VD and the cell remains strongly depolarized and fires tonically. VD oscillations resume soon after PS stimulation. B. PS-derived EPSPs in VD disappear in the presence of curare, and the cell oscillates throughout PS discharge. Horizontal scale bar, 2 sec; vertical scale bar, 10 $\mathrm{mV}$.

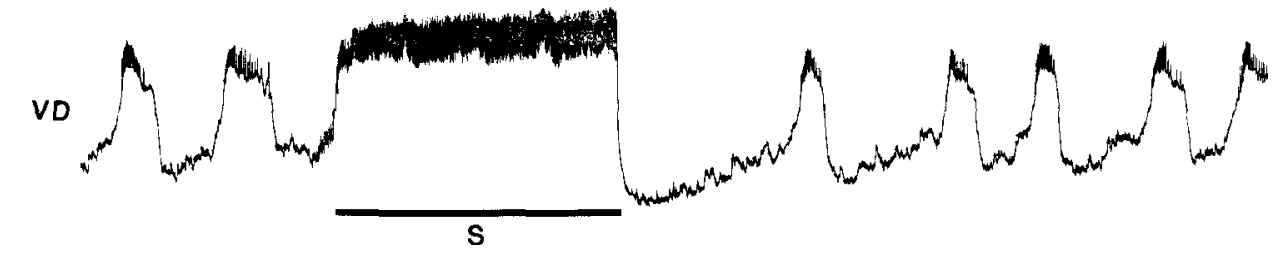

B

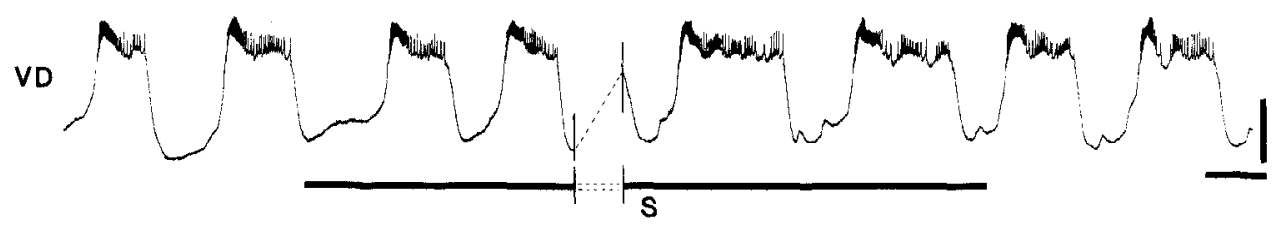




\section{A}

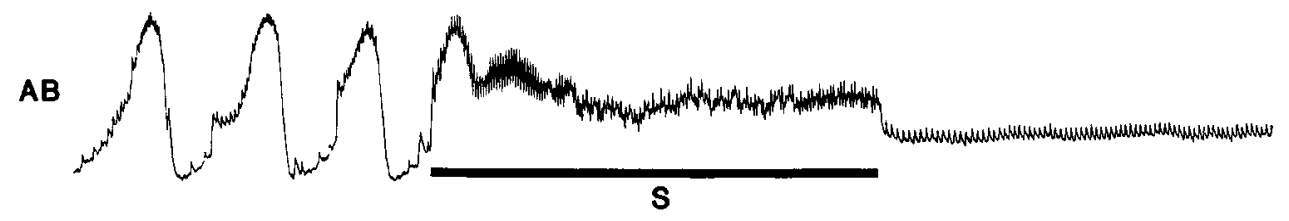

B1
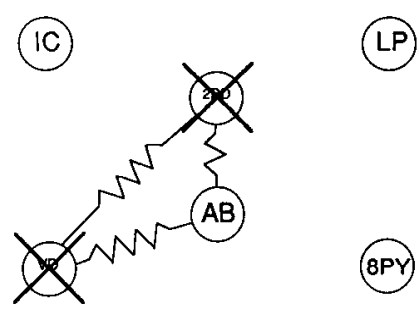

B2

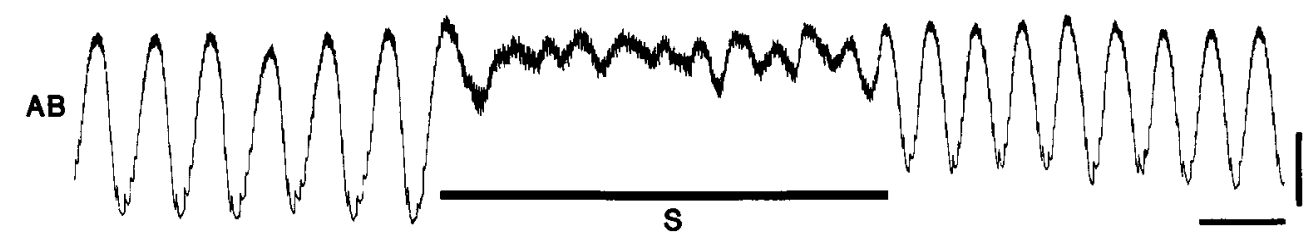

Figure 8. The PS neuron transiently excites the $\mathrm{AB}$ neuron. $A$, With the pyloric network, intact, PS discharge, elicited by axonal stimulation in the ivn $(S ; 5 \mathrm{sec}, 30 \mathrm{~Hz}$ ), evokes EPSPs and a concomitant depolarization of $\mathrm{AB}$, followed by a complete and long-lasting cessation of AB's oscillatory activity. $B$, When $\mathrm{AB}$ is isolated $\left(B_{l}\right)$ by photoinactivating electrically coupled neurons (PD, VD), PS discharge still evokes EPSPs and the transient depolarization of $A B$, but no longer causes the subsequent cessation of $\mathrm{AB}$ oscillation $\left(B_{2}\right)$. Horizontal scale bar, $1 \mathrm{sec}$; vertical scale bar, $15 \mathrm{mV}$.

coupling between the 3 pacemaker cells and would explain the cessation of AB oscillation after PS firing, although the latter's direct effect on $\mathrm{AB}$ is activity-dependent excitation (see Fig. $8 B$ ). In addition, when oscillations cease in the pacemaker neurons and the constrictor LP, the constrictor neurons PY are no longer rhythmically repolarized by synaptic inhibition and remain depolarized without bursting.

Suppressive effects on the regenerative properties of the PD and LP neurons also appear to be mainly responsible for the functional reconfigurations of the pyloric network that occur during tonic low-frequency discharges of PS (Cazalets et al., 1990). This is due to two interrelated factors. First, at a given discharge frequency PS suppression of the LP neuron is considerably longer than that of the PD neurons (Fig. 2). Thus, in an intact pyloric network, when oscillations resume in the pacemaker neurons, after a brief PS discharge a biphasic (PD-PY) pyloric pattern is expressed before the normal triphasic (PDLP-PY) pattern resumes. Second, the suppressive effects of PS are not all or none (Fig. 2), but can give rise to graded increases in burst period and decreases in burst duration and spike frequency of the PD and LP neurons.

A similarly suppressive control of oscillatory activity has been proposed for the R15 neuron in Aplysia using electrical stimulation of input nerves (Parnas et al., 1974; Adams et al., 1980), intrasomatic depolarization of an identified presynaptic cell (Wilson and Wachtel, 1978), and bath application of dopamine (Benson and Adams, 1987; see also review by Adams and Benson, 1985). The originality of the action of PS is that it affects an ensemble of neurons comprising a motor pattern generating network.

\section{Long-lasting activating effects of PS}

This effect of PS invokes the PY and IC neurons. First, unlike the suppressive control of PD and LP, the long-lasting activation of $\mathrm{PY}$ and $\mathrm{IC}$ does not directly involve the oscillatory properties of these neurons. Second, the long-lasting activation is different for the neurons. After PS discharge the IC neuron continues to oscillate, although at higher oscillation and firing frequencies. The PY neurons, however, are depolarized above the voltage range where repolarizing conductances can be expressed, and consequently, they remain tonically active only. Thus, although the intrinsic ability of PY neurons to oscillate remains unaffected, the functional consequences of PS discharge is nonetheless to suppress their rhythmic activity. A comparable action has been described in Aplysia, where the R15 neuron may stop oscillating and discharge tonically in response to stimulation of a presynaptic input (Parnas et al., 1974).

\section{Transient activating effects of $P S$}

This influence of PS concerns the dilator neurons (PD, AB, and VD) which display large EPSPs in response to PS action potentials. The summation of these EPSPs strongly depolarizes the dilator neurons and causes high-frequency discharge during PS

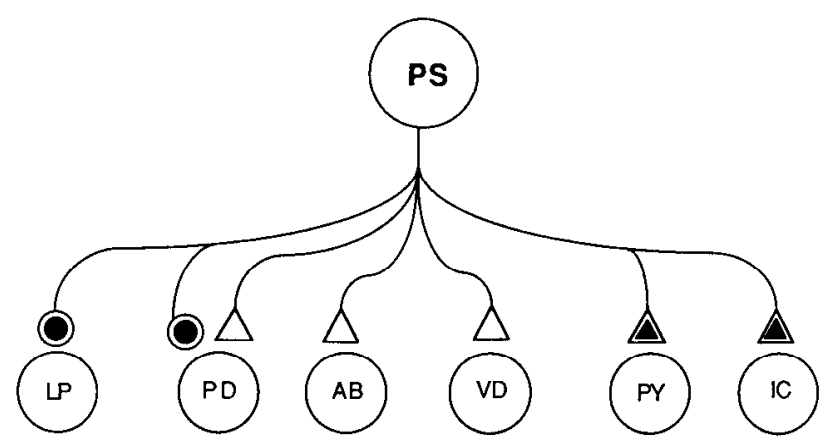

Figure 9. Summary diagram of the 3 types of influence of PS on pyloric neurons: (1) transient excitatory effect on PD, $A B$, and VD neurons, mediated by brief discrete EPSPs (open triangles); (2) long-lasting inactivating effect on PD and LP neurons, resulting in hyperpolarization and loss of oscillatory properties (filled circles); (3) long-lasting activating effect on the PY and IC neurons, resulting in depolarization without modification of oscillatory properties (filled triangles). 
firing. An interesting observation here is that spontaneous bursts of EPSPs that are not timed with the pyloric rhythm, but are similar to those elicited by PS, are occasionally seen in pyloric pacemaker neurons in our in vitro preparations (J. R. Cazalets, unpublished observations). In these instances, $\mathrm{PD}$ and $\mathrm{AB}$ discharge (induced by the spontaneous EPSP trains) consists of 510 -sec high-frequency bursts of spikes occurring every $50 \mathrm{sec}$. These bursts are phase-locked to bursts of spikes in the CD2 neuron, which is a dilator motor neuron of the cardiac sac (Vedel and Moulins, 1977). Therefore, a possible functional consequence of the EPSP-evoked activation of PD-AB by the PS neuron is that the PD motor neurons (and hence the pyloric dilator muscles) can participate in a rhythmic activity other than the pyloric rhythm.

\section{Multiple effects of $P S$}

PS discharge exerts a dual influence on the dilator neurons PD: a short-term synaptic effect via discrete EPSPs, and a long-term effect (suppression of oscillatory properties), which seems to be related to a neuromodulatory process (Kaczmarek and Levitan, 1987). Since preliminary immunohistochemical data indicate that PS contains a FMRFamide-like peptide (P. Meyrand, personal communication), the possibility arises that the dual action exerted by PS on the PD neurons is mediated by 2 cotransmitters. However, bath application of FMRFamide on the STG of the lobster Panulirus interruptus does not reproduce any effect of PS discharge (Hooper and Marder, 1984; Marder et al., 1987). Moreover, in instances where the physiological effect of a peptide cotransmitter is known (O'Shea and Adams, 1981; Lundberg and Hökfelt, 1983; Bishop et al., 1987), the peptide exerts its modulatory influence in synergy with the short-term-acting transmitter. The dual physiological effects of PS on PD discharge are somewhat akin to thosc of previously described multiaction interneurons in Aplysia, which provoke different effects on the same postsynaptic neuron via a single transmitter (Kehoe, 1972; Gardner and Kandel, 1977). Even more reminiscent are the responses of $\mathrm{C}$ cells in amphibian sympathetic ganglia (Dodd and Horn, 1983; Adams and Galvan, 1986) and of neurons of parasympathetic ganglia in amphibians and cat (Hartzell et al., 1977; Gallagher et al., 1982), whereby stimulation of preganglionic cholinergic fibers induces a rapid EPSP in addition to a prolonged postsynaptic hyperpolarization.

The PS neuron also exerts different effects on each pyloric neuron. Such differential control of elements in a pattern-generating network has not been widely reported in the literature. One example, however, that is comparable to the multiple effects of PS, is the influence of the histaminergic modulatory neuron C2 on several neurons of the feeding motor circuitry in Aplysia (Chicl ct al., 1986; Weiss et al., 1986).

In the stomatogastric nervous system, another modulatory neuron, the anterior pyloric modulator (APM), has been shown to influence all the neurons of the pyloric circuit (Nagy and Dickinson, 1983). APM, unlike PS, evokes a general activation of the pyloric network through the induction or potentiation of oscillatory properties in target neurons (Dickinson and Nagy, 1983). Moreover, the APM neuron was recently shown to exert multiple effects on different neurons of another circuit in the STG, the gastric mill network (Dickinson et al., 1988). Similarly, serotonin, which is present in sensory neurons that feed back to pyloric neurons (Katz and Harris-Warrick, 1987), appears to exert selective modulatory effects on the different pyloric neurons when bath-applied to the STG (Flamm and Harris-War- rick, 1986). It is likely, therefore, that the type of action of the PS modulatory neuron (selective control over the different neurons of a network) is of more general occurrence.

\section{Comparison between the PS neurons of Homarus and the ivn- TF of Palinurid lobsters}

Several common anatomical features and some similarities in their effects on the pyloric network suggest that the PS neurons of Homarus are homologous to 2 neurons, the ivn-through fibers (ivn-TF), previously identified in the spiny lobsters Panulirus interruptus and Panulirus argus (Dando and Selverston, 1972). However, other striking differences in their physiological effects (notably the long-term influence of PS neurons) indicate that if these neuron types are homologs, their functions have become substantially modified in the 2 decapod families.

First, although the cell bodies of PS neurons are located in the ivn, close to the OG, whilc those of ivn-TF are found at the entrance of the ivn to the brain, the 2 cell types exhibit similar axonal geometries, in both cases an axon projecting in the stn to the STG and branches in the ions and sons to the COGs. Another argument for homology is that the ivn of the spiny lobster contains 8 axons running the entire length of the nerve, 2 of them belonging to the ivn-TF (Claiborne and Selverston, 1984b), whereas in Homarus the ivn contains 8 axons only between the OG and the PS cell bodies and 6 axons between the PS cell bodies and the brain (Liliane Nonnotte, personal communication). Second, both the ivn-TF and the PS neurons evoke a rapid curare-sensitive EPSP in dilator neurons (PD, AB, VD; Russell and Hartline, 1981; Sigvardt and Mulloney, 1982; and present paper). Third, the PS neurons appear also to be implicated in the rhythmic activity of the cardiac sac, their spontaneous discharges occurring in phase with bursts in the cardiac sac motor neuron $\mathrm{CD}_{2}$ (Cazalets, unpublished observations). Similar cardiac sac activity and phase relations with $\mathrm{CD}_{2}$ have been observed for ivn-TF (Moulins and Vedel, 1977).

Despite these similarities, however, fundamental functional differences exist between the PS neurons and the ivn-TF. First, the PS neurons in Homarus evoke a long-lasting suppression of oscillatory properties in PD, leading to a prolonged cessation of its rhythmic activity. In Panulirus, the ivn-TF evoke a slow IPSP in PD, which can lead to cessation of rhythmic dilator activity, but it is a transient effect that does not outlast the discharge of ivn-TF. By contrast, the ivn-TF cause a long-lasting promotion of PD oscillatory properties (Russell and Hartline, 1981). Second, in Panulirus the ivn-TF have no direct effect on constrictor neurons LP, PY, and IC (Russell and Hartline, 1982; Sigvardt and Mulloney, 1982), whereas in Homarus the PS neurons strongly modify all the constrictors, causing long-lasting inactivation of LP (Fig. 2) and long-lasting activation of PY and IC (Figs. 5 and 6). In conclusion, on the basis of their longlasting actions alone, it appears that the PS neurons and the ivn-TF have opposite effects on the pyloric network, with PS neurons tending to suppress rhythmicity while the ivn-TF tends to enhance it. Finally, the PS neurons and the ivn-TF probably use different transmitters. In Panulirus the ivn-TF were shown to contain histamine, which mediates their inhibition of the PD neurons but does not influence the pyloric constrictor neurons (Claiborne and Selverston, 1984a). For Homarus, bath application of $10^{-5} \mathrm{M}$ histamine to the STG also results in a strong inhibition of the PD neuron although, at this concentration, LP is unaffected and remains able to produce regenerative depolarizations (Cazalets, unpublished observations). It is improb- 
able, therefore, that the Homarus PS ncurons, which primarily influence the LP neuron, release histamine.

able, therefore, that the Homarus PS neurons, which primarily influence the LP neuron, release histamine.

In conclusion, if the ivn-TF and the PS neurons are actual homologous afferent pathways to the STG, they obviously subserve different functions. It remains to determine whether these differences derive primarily from modifications in the input elements themselves (transmitters used, release mechanisms), or whether the postsynaptic pyloric elements are also implicated (receptor properties, transduction mechanisms).

\section{References}

Adams, P. R., and M. Galvan (1986) Voltage-dependent currents of vertebrate neurons and their role in membrane excitability. Adv. in Neurol. 44: 137-170.

Adams, W. B., and J. A. Benson (1985) The generation and modulation of endogenous rhythmicity in the Aplysia bursting pacemaker neurone R15. Prog. Biophys. Mol. Biol. 46: 1-49.

Adams, W. B., I. Parnas, and I. B. Levitan (1980) Mechanism of longlasting synaptic inhibition in Aplysia neuron R15. J. Neurophysiol. 44: $1148-1160$

Anderson, W.W. (1980) Synaptic Mechanisms Generating Nonspiking Network Oscillations in the Stomatogastric Ganglion of the Lobster, Panulirus interruptus. Ph.D. Dissertation, University of Oregon, Eugene.

Bal, T., F. Nagy, and M. Moulins (1988) The pyloric central pattern generator in crustacea: A set of conditional neuronal oscillators. J. Comp. Physiol. A 163: 715-727.

Benson, J. A., and W. B. Adams (1987) The control of rhythmic neuronal firing. In Neuromodulation. The Biochemical Control of Neuronal Excitability, L. K. Kaczmarek and I. B. Levitan, eds., pp. 100-1 18, Oxford U. P., New York.

Berry, M. S., and V. W. Pentreath (1976) Criteria for distinguishing between monosynaptic and polysynaptic transmission. Brain Res. 10.5: $1-20$.

Bidaut, M. (1980) Pharmacological dissection of pyloric network of the lobster stomatogastric ganglion using picrotoxin. J. Neurophysiol. 44: 1089-1101.

Bishop, C. A., J. J. Wine, F. Nagy, and M. R. O'Shea (1987) Physiological consequences of a peptide cotransmitter in a crayfish nervemuscle preparation. J. Neurosci. 7: 1769-1779.

Cazalets, J. R., I. Cournil, M. Geffard, and M. Moulins (1987a) Suppression of oscillatory activity in crustacean pyloric neurons: Implication of GABAergic inputs. J. Neurosci. 7: 2884-2893.

Cazalets, J. R., F. Nagy, and M. Moulins (1987b) Suppressive control of a rhythmic central pattern generator by an identified modulatory neuron in crustacea. Neurosci. Lett. 81: 267-272.

Cazalets, J. R., F. Nagy, and M. Moulins (1990) Suppressive control of the crustacean pyloric network by a pair of identified interneurons. I. Modulation of the motor pattern. J. Neurosci. 10: 448-457.

Chiel, H. J., K. R. Weiss, and I. Kupfermann (1986) An identified histaminergic neuron modulates feeding motor circuitry in Aplysia. J. Neurosci. 6: 2427-2450.

Claiborne, B. J., and A. I. Selverston (1984a) Localization of stomatogastric IV neuron cell bodies in lobster brain. J. Comp. Physiol. A 154: $27-32$

Claiborne, B. J., and A. I. Selverston (1984b) Histamine as a neurotransmitter in the stomatogastric nervous system of the spiny lobster. J. Neurosci. 4: 708-721.

Dando, M. R., and A. I. Selverston (1972) Command fibres from the supraoesophageal ganglion to the stomatogastric ganglion in Panulirus argus. J. Comp. Physiol. 78: 138-175.

Dickinson, P. S., and F. Nagy (1983) Control of a central pattern generator by an identified modulatory interneurone in Crustacea. II. Induction and modification of plateau properties in pyloric neurones. J. Exp. Biol. 105: 59-82.

Dickinson, P. S., F. Nagy, and M. Moulins (1988) Control of central pattern generators by an identified neurone in crustacea: Activation of the gastric mill motor pattern by a neurone known to modulate the pyloric network. J. Exp. Biol. 136: 53-87.
Dodd, J., and J. P. Horn (1983) Muscarinic inhibition of sympathetic c neurones in the bullfrog. J. Physiol. (Lond.) 334: 271-291.

Eisen, J. S., and E. Marder (1982) Mechanisms underlying pattern generation in lobster stomatogastric ganglion as determined by selective inactivation of identified neurons. III. Synaptic connections of electrically coupled pyloric neurons. J. Neurophysiol. 48: 1392-1415.

Flamm, K. E., and K. M. Harris-Warrick (1986) Aminergic modulation in lobster stomatogastric ganglion. II. Target neurons of dopamine, octopamine, and serotonin within the pyloric circuit. J. Neurophysiol. 55: 866-881

Gallagher, J. P., W. H. Griffith, and P. Shinnick-Gallagher (1982) Cholinergic transmission in cat parasympathetic ganglia. J. Physiol. (Lond.) 332: 473-486.

Gardner, D., and E. R. Kandel (1977) Physiological and kinetic properties of cholinergic receptors activated by multiaction interneurons in buccal ganglia of Aplysia. J. Neurophysiol. 40: 333-348.

Gola, M., and A. I. Selverston (1981) Ionic requirements for bursting activity in lobster stomatogastric neurons. J. Comp. Physiol. A 145. 191-207.

Hartzell, H. C., S. W. Kuffler, R. Stickgold, and D. Yoshikami (1977) Synaptic excitation and inhibition resulting from direct action of acetylcholine on two types of chemoreceptors on individual amphibian parasympathetic neurones. J. Physiol. (Lond.) 271: 817-846.

Hooper, S. L., and E. Marder (1984) Modulation of a central pattern generator by two neuropeptides, proctolin and FMRFamide. Brain Res. 305: 186-191.

Kaczmarek, L. K., and I. B. Levitan (1987) Neuromodulation. The Biochemical Control of Neuronal Excitability, Oxford U. P., New York.

Katz, P. S., and R. M. Harris-Warrick (1987) Serotonergic primary sensory neurons feed back to motor neurons in the crab stomatogastric ganglion. Soc. Neurosci. Abstr. 13: 821.

Kehoe, J. S. (1972) The physiological role of three acetylcholine receptors in synaptic transmission in Aplysia. J. Physiol. (Lond.) 225: $147-172$.

Leake, L. D., and R. J. Walker (1980) Invertebrate Neuropharmacology, Blackie, Glasgow.

Lundberg, J. M., and T. Hökfelt (1983) Coexistence of peptides and classical neurotransmitters. Trends Neurosci. 6: 325-333.

Marder, E. (1987) Neurotransmitters and neuromodulators. In The Crustacean Stomatogastric System. A Model for the Study of Central Nervous Systems, A. I. Selverston and M. Moulins, eds., pp. 263300, Springer, New York.

Marder, E., and D. Paupardin-Tritsch (1978) The pharmacological properties of some crustacean neuronal acetylcholine, $y$-aminobutyric acid, and L-glutamate responses. J. Physiol. (Lond.) 280: 213-236.

Marder, E., R. L. Calabrese, M. P. Nusbaum, and B. Trimmer (1987) Distribution and partial characterization of FMRFamide-like peptides in the stomatogastric nervous systems of the rock crab, Cancer borealis, and the spiny lobster, Panulirus interruptus. J. Comp. Neurol. 259: 150-163.

Miller, J. P., and A. I. Selverston (1979) Rapid killing of single neurons by irradiation of intracellularly injected dye. Science 206: 702-704.

Miller, J. P., and A. I. Selverston (1982) Mechanisms underlying pattern generation in lobster stomatogastric ganglion as determined by selective inactivation of identified neurons. II. Oscillatory properties of pyloric neurons. J. Neurophysiol. 48: 1378-1391.

Moulins, M., and I. Cournil (1982) All-or-none control of the bursting properties of the pacemaker neurons of the lobster pyloric pattern generator. J. Neurobiol. 13: 447-458.

Moulins, M., and J. P. Vedel (1977) Programmation centrale de l'activité motrice rhythmique du tube digestifantérieur chez les Crustacés décapodes. J. Physiol. 73: 471-510.

Nagy, F., and P. S. Dickinson (1983) Control of a central pattern generator by an identified modulatory interneurone in crustacea. I. Modulation of the pyloric motor output. J. Exp. Biol. 105: 33-58.

Nagy, F., J. A. Benson, and M. Moulins (1985) Cholinergic inputs reduce a steady outward $\mathrm{K}^{+}$current allowing activation of a $\mathrm{Ca}^{2+}$ conductance which underlies the burst-generating oscillations in lobster pyloric neurons. Soc. Neurosci. Abstr. 11: 1022.

O'Shea, M., and M. E. Adams (1981) Pentapeptide (proctolin) associated with an identified neuron. Science 213: 567-569.

Parnas, I., D. Armstrong, and F. Strumwasser (1974) Prolonged excitatory and inhibitory synaptic modulation of a bursting pacemaker neuron. J. Neurophysiol. 37: 594-608. 
Robertson, R. M., and M. S. Laverack (1979) Oesophageal sensors and their modulatory influence on oesophageal peristalsis in the lobster, Homarus gammarus. Proc. R. Soc. Lond. B 206: 235-263.

Russell, D. F., and D. K. Hartline (1981) A multiaction synapse evoking both EPSPs and enhancement of endogenous bursting. Brain Res. 223: $19-38$.

Russell, D. F., and D. K. Hartline (1982) Slow active potentials and bursting motor patterns in pyloric network of the lobster, Panulirus interruptus. J. Neurophysiol. 48: 914-937.

Sigvardt, K. A., and B. Mulloney (1982) Properties of synapses made by IVN command-interneurones in the stomatogastric ganglion of the spiny lobster Panulirus interruptus. J. Exp. Biol. 97: 153-168.
Vedel, J. P., and M. Moulins (1977) Functional properties of interganglionic motor neurons in the stomatogastric nervous system of the rock lobster. J. Comp. Physiol. A 118: 307-325.

Weiss, K. R., E. Shapiro, and I. Kupfermann (1986) Modulatory synaptic actions of an identified histaminergic neuron on the serotonergic metacerebral cell of Aplysia. J. Neurosci. 6: 2393-2402.

Wilson, W. A., and H. Wachtel (1978) Prolonged inhibition in burst firing neurons: Synaptic inactivation of the slow regenerative inward current. Science 202: 772-775. 